\title{
Comparisons of observational data sets for evaluating the CMIP5 precipitation extreme simulations over Asia
}

\author{
Siyan Dong ${ }^{1, *}$, Ying Sun ${ }^{1,2}$ \\ ${ }^{1}$ Laboratory for Climate Studies, National Climate Center, China Meteorological Administration, Beijing 100081, PR China \\ ${ }^{2}$ Joint Center for Global Change Studies, Beijing 100081, PR China
}

\begin{abstract}
The accurate simulation of precipitation extremes in climate models is important for the understanding of future climate change and its impacts. Due to the poor coverage and the lack of uniformity of observational precipitation extreme data in Asia, it is difficult to evaluate whether existing climate models can accurately reproduce the patterns of and changes in precipitation extremes. The present study presents a comparison between 3 observational data sets and CMIP5 models and shows that improving the data coverage in the future is of great significance for understanding precipitation extreme changes in Asia. The 3 observational data sets show good consistency with the models in the mid- and high-latitude regions of Asia, where the data generally have good coverage. Meanwhile, the differences between the observations are obvious in the lowlatitude region, and the differences between the models are also large. Although these discrepancies may be related to different operational orders and interpolation methods, the spatial coverage of data can constitute an important factor leading to such differences at low latitudes. The results for the mid-latitude region show little change in the new Asian observation data set (ADEX) compared with in HadEX2, but the trend of precipitation extreme intensity indices in ADEX are closer to the simulated trend than in HadEX2 for the high-latitude region. Furthermore, the differences in the intensity indices between the observations and models are larger than those in the frequency indices, indicating that the simulated and projected values of the intensity indices are higher than those of the frequency indices. In summary, there are differences between the 3 datasets and CMIP5 models, especially for low-latitudes and the intensity indices.
\end{abstract}

KEY WORDS: Precipitation extremes · Observational data sets $\cdot$ CMIP5 $\cdot$ Model evaluation

\section{INTRODUCTION}

Previous studies have shown that anthropogenic influences can be identified in changes in the duration, frequency and intensity of precipitation extremes (Zhang et al. 2007, Polson et al. 2013, Zhang et al. 2013, IPCC 2014, Fischer \& Knutti 2015). In addition, such influences are expected to increase the intensities and frequencies of floods and droughts, and impose negative effects on the environment, economy and society throughout Asia (IPCC 2014). Freychet et al. (2016) suggested that precipitation

\footnotetext{
*Corresponding author: dongsy@cma.gov.cn
}

extremes with a greater intensity and higher frequency are likely to increase over East Asia in the future. Furthermore, some authors have attempted to evaluate precipitation extremes at the national scale over Asia (Ou et al. 2013, Sillmann et al. 2013a, Jiang et al. 2015, Freychet et al. 2016). For example, Ou et al. (2013) suggested that the Coupled Model Intercomparison Project Phase 5 (CMIP5) models overestimate precipitation extremes in western China and high-altitude regions compared with station data in China, although those models simulate the precipitation extremes in eastern China very well. Jiang et al.

() The authors 2018. Open Access under Creative Commons by Attribution Licence. Use, distribution and reproduction are unrestricted. Authors and original publication must be credited. 
(2015) compared 4 precipitation extreme indices between different CMIP5 models; in comparison with observational station data in China, they found that the simulated data in eastern China are more reliable than those in western China. However, such evaluation studies have often focused on limited precipitation extreme indices over Asia, and focused only on the national scale (e.g. China, where the amount of daily observational data is large) or on Asia as a whole for global analysis (Sillmann et al. 2013a), the results of which are insufficient for comprehensively understanding the regional differences between models and observational precipitation extremes in different latitudinal regions across Asia.

In fact, constraining the spatial and temporal differences between various observational data sets and models can represent a major challenge for the evaluation of models across Asia. Wan et al. (2013) found that the incomplete spatial coverage of observational data records resulted in increased sampling errors of trend estimates, making it more difficult to detect statistically significant trends. The HadEX2 data set has often been used for studying precipitation extremes; however, the spatial coverage of the HadEX2 gridded product for precipitation extremes is far from ideal (Alexander et al. 2006, Sillmann et al. 2013a), and the improvements to the HadEX2 data set in the coverage of precipitation extremes are less impressive than those of temperature stations (Donat et al. 2013, Alexander 2016). Furthermore, Sillmann et al. (2013a) found that compared with HadEX2, CMIP5 models generally underestimate intensity indices (e.g. maximum 5 d precipitation [Rx5day] and Simple day intensity index [SDII], especially SDII) - for which HadEX2 lies outside of the CMIP5 model range - and overestimate the number of consecutive wet days (CWD). This situation also occurs in Asia. Some authors have even noted that HadEX2 may not be the most appropriate data set for evaluating precipitation extremes in climate models, given the order of operations used in the construction of HadEX2 (Donat et al. 2013, Alexander \& Arblaster 2017). Alternatively, in recent years, the Asian Precipitation - Highly-Resolved Observational Data Integration Towards Evaluation of Water Resources (APHRODITE) project has developed daily gridded precipitation data (Yatagai et al. 2012). This observational data set currently comprises high-resolution gridded land precipitation data covering the entire Asian region, but some authors have argued that the data set exhibits obvious deviations from observational station data when describing the frequency, intensity and climatology in addition to the long-term changes in different grades of precipitation throughout China (Han \& Zhou 2012, Yin et al. 2015). Additionally, the temporal coverage of APHRODITE data is shorter than that of HadEX2.

In short, there is a lack of comprehensive research focusing on climate model evaluations over Asia because of the limited amount of available observational data sets. Consequently, to improve the spatial and temporal coverage in Asia, a new daily Asian observational extreme indices data set (hereafter called ADEX) was developed in 2013 by the joint World Meteorological Organization (WMO) CCl/ CLIVAR/JCOMM Expert Team on Climate Change Detection and Indices (ETCCDI) with help from scientists originating from various countries in Asia. Compared with HadEX2, this observational data set has a greater spatial coverage and provides more detailed information about climate extremes over Asia. The improvement in the spatial and temporal coverage for observations over Asia may be helpful for better understanding the changes in precipitation extremes, and for applying them to projection, detection and attribution endeavors.

Unfortunately, substantial discrepancies are likely to exist among various observational data sets (HadEX2, APHDEX and ADEX), and thus the use of various observational data sets may lead to notable uncertainties when they are used to evaluate models. Accordingly, this paper focuses on evaluating the CMIP5 multi-model ensemble with 3 observational data sets (ADEX, HadEX2 and APHDEX). We quantitatively measured the differences between the models and the 3 observational data sets with regard to the $47 \mathrm{yr}$ mean climatology in precipitation extreme indices and their trends during 1961-2007. We also provide observational uncertainties using 3 independent observational data sets over Asia. Most importantly, ADEX will provide important information that will be useful for understanding climate change and its impacts throughout Asia.

\section{DATA AND METHODOLOGY}

\subsection{Precipitation extreme indices}

The 10 precipitation extremes developed by the ETCCDI (http://etccdi.pacificclimate.org/list_27_ indices.shtml) and used in this study are shown in Table 1. These 10 different precipitation extreme indices include intensity indices composed of absolute intensity indices (Rx1day and Rx5day), relative intensity indices (R95p and R99p) and a simple daily inten- 
sity index (SDII), in addition to frequency indices (R10mm and R20mm), duration indices (including CWD and consecutive dry days [CDD]) and annual precipitation total (PRCPTOT).

\subsection{Observations}

\subsubsection{HadEX2}

HadEX2 is a global land-based gridded climate extremes data set produced through the coordination of the joint WMO CCl/CLIVAR/JCOMM ETCCDI. It is an updated version of HadEX (Alexander et al. 2006) and contains more station data and covers a much longer period than HadEX (Donat et al. 2013, accessed at www.climdex.org/index.html). The precipitation extreme indices are based on daily observations from approximately 11600 precipitation stations gridded on a $2.5 \times 3.75^{\circ}$ (latitude $\times$ longitude) grid from 1901 to 2010 . Angular-distance weighting was used to interpolate the station data onto the required grid.

\subsubsection{APHRODITE daily gridded data set}

APHRODITE comprises gridded rainfall data from the APHRODITE project (Yatagai et al. 2012, accessed at www.chikyu.ac.jp/precip). This data set has been applied to climate change and water cycle research in addition to the high-resolution model results of model inspections and other fields. The present study analyses the APHRO_MA V1003R1 data set, which describes the precipitation characteristics of Monsoon Asia (MA) and mainly includes China, Japan, Mongolia, India, all countries in Southeast Asia, and some countries in Central Asia. We selected the data set with a resolution of $1 \times 1^{\circ}$ and used the period from 1961 to 2007 for analysis. The data set is also subjected to quality control processes (Yatagai et al. 2012), and in the present study, the 10 annual precipitation extreme indices were calculated from the daily precipitation gridded data and we refer to the precipitation extreme indices data as the APHDEX data set.

Table 1. Definition of the 10 extreme precipitation indices used in this study

\begin{tabular}{|c|c|c|c|}
\hline $\begin{array}{l}\text { Extreme } \\
\text { indices }\end{array}$ & Category & Definition and calculation of index & Unit \\
\hline Rx1day & $\begin{array}{l}\text { Intensity } \\
\text { indices }\end{array}$ & $\begin{array}{l}\text { Monthly maximum } 1 \mathrm{~d} \text { precipitation: Let RR } i j \text { be the daily precipitation amount on } \\
\text { day } i \text { in period } j \text {. The maximum } 1 \mathrm{~d} \text { value for period } j \text { is: } \operatorname{Rx} 1 \mathrm{day} j=\max (\mathrm{R} R i j)\end{array}$ & $\mathrm{mm}$ \\
\hline Rx5day & $\begin{array}{l}\text { Intensity } \\
\text { indices }\end{array}$ & $\begin{array}{l}\text { Monthly maximum } 5 \mathrm{~d} \text { precipitation: Let } \mathrm{RR} k j \text { be the precipitation amount for the } 5 \mathrm{~d} \\
\text { interval ending on day } k \text { in period } j \text {. Then, the maximum } 5 \mathrm{~d} \text { values for period } j \text { are: } \\
\operatorname{Rx} 5 \mathrm{da} y j=\max (\mathrm{RR} k j)\end{array}$ & $\mathrm{mm}$ \\
\hline R95p & $\begin{array}{l}\text { Intensity } \\
\text { indices }\end{array}$ & $\begin{array}{l}\text { Annual total daily precipitation when } R R>95 \mathrm{p} \text {. Let } \mathrm{RR} w j \text { be the daily precipitation } \\
\text { amount on a wet day } w(\mathrm{RR} \geq 1.0 \mathrm{~mm}) \text { in period } i \text {, and let } \mathrm{RR} w n 95 \text { be the } 95 \text { th } \\
\text { percentile of the precipitation on wet days during } 1961-1990\end{array}$ & $\mathrm{~mm}$ \\
\hline R99p & $\begin{array}{l}\text { Intensity } \\
\text { indices }\end{array}$ & $\begin{array}{l}\text { Annual total PRCP when } R R>99 p \text { : Let } R R w j \text { be the daily precipitation amount on a } \\
\text { wet day } w(\mathrm{RR} \geq 1.0 \mathrm{~mm}) \text { in period } i \text {, and let RR } w n 99 \text { be the 99th percentile of the } \\
\text { precipitation on wet days during } 1961-1990\end{array}$ & $\mathrm{~mm}$ \\
\hline PRCPTOT & & $\begin{array}{l}\text { Annual total precipitation on wet days: Let RRij be the daily precipitation amount on } \\
\text { day } i \text { in period } j\end{array}$ & $\mathrm{~mm}$ \\
\hline SDII & $\begin{array}{l}\text { Intensity } \\
\text { indices }\end{array}$ & $\begin{array}{l}\text { Simple precipitation intensity index: Let } \mathrm{RR} w j \text { be the daily precipitation amount on } \\
\text { wet days } w(\mathrm{RR} \geq 1 \mathrm{~mm}) \text { in period } j \text {. If } W \text { represents the number of wet days in } j\end{array}$ & $\mathrm{~mm} \mathrm{~d}^{-1}$ \\
\hline $\mathrm{R} 10 \mathrm{~mm}$ & $\begin{array}{l}\text { Frequency } \\
\text { indices }\end{array}$ & $\begin{array}{l}\text { Annual number of days when PRCP } \geq 10 \mathrm{~mm} \text { : Let RRij be the daily precipitation } \\
\text { amount on day } i \text { in period } j \text {. Count the number of days where: RRij } \geq 10 \mathrm{~mm} \text {. }\end{array}$ & d \\
\hline $\mathrm{R} 20 \mathrm{~mm}$ & $\begin{array}{l}\text { Frequency } \\
\text { indices }\end{array}$ & $\begin{array}{l}\text { Annual number of days when PRCP } \geq 20 \mathrm{~mm} \text { : Let RRij be the daily precipitation } \\
\text { amount on day } i \text { in period } j \text {. Count the number of days where: RRij } \geq 20 \mathrm{~mm} \text {. }\end{array}$ & d \\
\hline CWD & $\begin{array}{l}\text { Duration } \\
\text { indices }\end{array}$ & $\begin{array}{l}\text { Maximum length of wet spell, maximum number of consecutive days with RR } \geq \\
1 \mathrm{~mm} \text { : Let RRij be the daily precipitation amount on day } i \text { in period } j \text {. Count the } \\
\text { largest number of consecutive days where: RRij } \geq 1 \mathrm{~mm}\end{array}$ & d \\
\hline CDD & $\begin{array}{l}\text { Duration } \\
\text { indices }\end{array}$ & $\begin{array}{l}\text { Maximum length of dry spell, maximum number of consecutive days with } \mathrm{RR}<1 \mathrm{~mm} \text { : } \\
\text { Let RRij be the daily precipitation amount on day } i \text { in period } j \text {. Count the largest } \\
\text { number of consecutive days where: RRij }<1 \mathrm{~mm}\end{array}$ & $\mathrm{~d}$ \\
\hline
\end{tabular}




\subsubsection{The new Asian extremes indices data set}

The new Asian extreme indices data set (ADEX) was developed through the joint efforts of the ETCCDI (e.g. Zhang et al. 2005, Peterson \& Manton 2008). A workshop was held in Nanjing, China, in 2013 involving scientists from 15 different nations throughout Asia who computed the extreme indices using long-term daily weather observational station data (Dong et al. 2018). This data set covers the period of 1951-2012. The participants were asked to check and test the data from the best and longest climate station records in their countries of origin for homogeneity using the RHtestsV3 software package (Wang \& Feng 2010), and homogenization was performed using HOMER (Mestre et al. 2013) (www.homogenisation. org/). To avoid the inclusion of erroneous observations in the analysis, the results were subjected to a second round of quality control. The Global Historical Climatology Network-Daily (GHCND) data set (Menne et al. 2012) was used to supplement additional stations or to expand the temporal completeness of the station data provided by all workshop participants, excluding those from China, for which the China National Meteorological Information Center (NMIC) was used as the data source (Cao et al. 2016).

Series that contained < 15 valid years between 1961 and 1990 were excluded in ADEX. This exclusion produced an effective number of series (consisting of approximately 2300 stations) for most indices over Asia, producing more stations over some countries than both HadEX2 and APHRODITE, and enhancing the temporal coverage of grid stations over Asia. To produce the ADEX gridded precipitation extreme indices data, we gridded values on $2.5 \times 3.75^{\circ}$ (latitude $\times$ longitude) grids (i.e. the HadEX2 grid size) by averaging the stations over each grid containing $\geq 1$ station; this procedure is different from the gridding methods used in both HadEX2 and APHDEX. The daily $1 \times 1^{\circ}$ gridded precipitation of APHRODITE was calculated to the annual precipitation extreme indices, and then the indices were regridded onto the HadEX2 grid size. Because only data from 1961 to 2007 were selected for APHRODITE, and because relatively small quantities of data are available prior to 1961 among all of the observational data sets, we used the pe- riod from 1961 to 2007 to analyze the climatology and area-averaged trends of the 3 observational data sets and CMIP5 models. HadEX2, APHDEX and ADEX were also masked in each data set grid box; therefore, all data sets had the same grids before the average trend and climatology were calculated. However, the Asian continent covers a large area from low to high latitudes, and the long-term changes and variability in precipitation extremes often vary regionally. Therefore, to conduct an in-depth analysis, Asia was divided into 3 regions (Fig. 1), namely, a low-latitude region $\left(5-25^{\circ} \mathrm{N}, 87.5-125^{\circ} \mathrm{E}\right)$, a mid-latitude region (25$40^{\circ} \mathrm{N}, 65-143.75^{\circ} \mathrm{E}$ ) and a high-latitude region (40$\left.57.5^{\circ} \mathrm{N}, 50-147.5^{\circ} \mathrm{E}\right)$.

\subsection{Model simulations}

The ETCCDI indices from the CMIP5 simulations (Taylor et al. 2012) are based on the results of Sillmann et al. (2013a,b) for historical simulations and the simulation of representative concentration pathways (RCPs). The precipitation extreme indices, which were not available, were performed using the software used in Sillmann et al. (2013a,b). Seventeen models (with each model having at least 3 runs, a total of 82 simulations) for all historical forcing experiments were used in this study (Table 2). Because most of these simulations end at 2005, but ADEX has the longest end year at 2012, RCP4.5 (an emissions scenario for which the radiative forcing value in the year 2100 is about $4.5 \mathrm{~W} \mathrm{~m}^{-2}$ above the pre-industrial value) simulations were used to extend these histori-

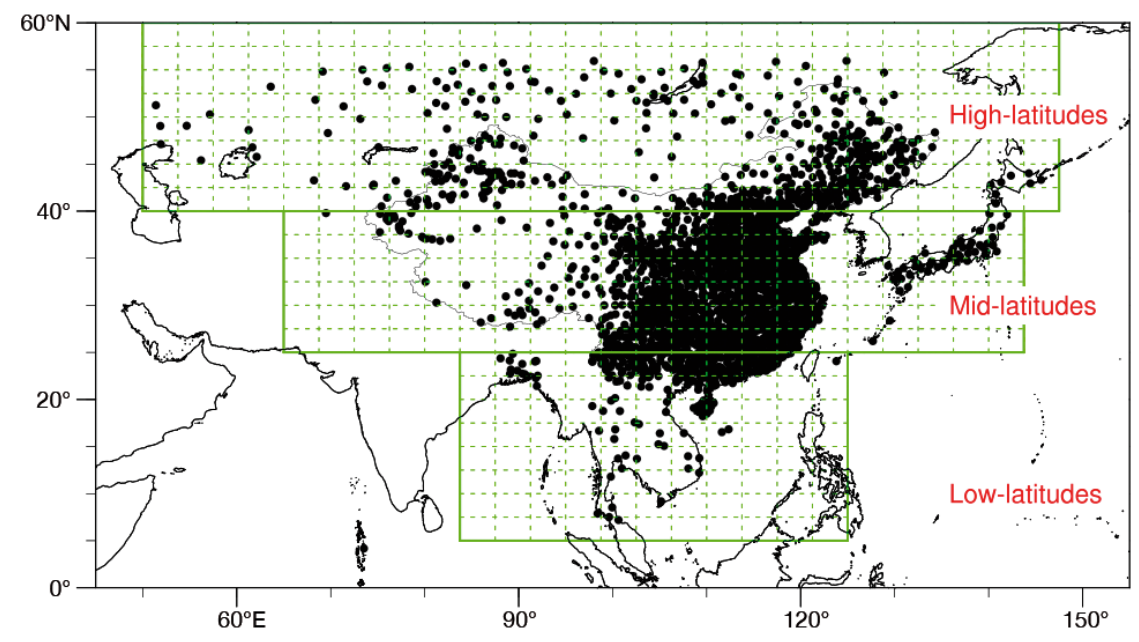

Fig. 1. Map of the station locations (black dots) and the 3 sub-regions used in the analyses. Regional boundaries are marked by green lines: low-latitude region $\left(5-25^{\circ} \mathrm{N}, 87.5-125^{\circ} \mathrm{E}\right)$; mid-latitude region $\left(25-40^{\circ} \mathrm{N}, 65-143.75^{\circ} \mathrm{E}\right)$; and high-latitude region $\left(40-57.5^{\circ} \mathrm{N}, 50-147.5^{\circ} \mathrm{E}\right)$ 
cal simulation data to 2012. For the purpose of evaluating the different-resolution models, all model data were interpolated onto $2.5 \times 3.75^{\circ}$ (latitude $\times$ longitude) grids (i.e. the HadEX2 grid size), and the ensemble mean multi-model values were obtained using the equally weighted arithmetic mean values of all members for each model. Table 2 depicts the institutions and the related model components of these models. Prior to regional averaging, the model simulation data were masked with 3 observational data sets to mimic the simultaneously available observational data (with each year of model data corresponding to each year of the 3 observational data sets if the 3 observational data sets all had existing values). Similar to the processing of observational data sets, the annual precipitation extreme indices were computed in each grid in the models.

\subsection{Model performance metrics}

We used indices of annual precipitation extremes in all 3 observational data sets and in the CMIP5 models. Accordingly, the linear least square regression method was used to analyze the corresponding trends.
To analyze the performance metrics of the various indices and models, the different model performances were assessed with the climatological root mean square errors (RMSEs) (Sheffield et al. 2013, IPCC 2013, Sillmann et al. 2013a, Dong et al. 2015), which are similar to those applied by Gleckler et al. (2008). The model simulation results and precipitation extreme indices were assessed and compared with $3 \mathrm{ob}-$ servational data sets (ADEX, HadEX2 and APHDEX). In this analysis, RMSEs were calculated for the annual mean values of the indices of precipitation extremes over all of Asia and its 3 sub-regions. The RMSE was calculated as follows:

$$
\operatorname{RMSE}=\sqrt{(X-Y)^{2}}
$$

where $X$ represents the model climatology of the precipitation extreme index, and $Y$ is the corresponding observational precipitation extreme.

All model RMSEs were then used to calculate the relative model error (RMSE') for each model defined as:

$$
\mathrm{RMSE}^{\prime}=\left(\mathrm{RMSE}-\mathrm{RMSE}_{\text {median }}\right) / \mathrm{RMSE}_{\text {median }}
$$

where RMSE $E_{\text {median }}$ is the median of the RMSEs for the 17 climate models.

\begin{tabular}{|c|c|c|}
\hline Model name & Institution (or group) & $\begin{array}{l}\text { olution (grids in } \\
\text { ritude by latitude } \\
\text { unit: degree) }\end{array}$ \\
\hline BCC-csm1-1 & Beijing Climate Center, China Meteorological Administration & $128 \times 64$ \\
\hline BCC-csm1-1-m & Beijing Climate Center, China Meteorological Administration & $128 \times 64$ \\
\hline CanESM2 & Canadian Centre for Climate Modelling and Analysis & $128 \times 64$ \\
\hline CNRM-CM5 & $\begin{array}{l}\text { Centre National de Recherches Météorologiques / Centre Européen de Recherche } \\
\text { et Formation Avancées en Calcul Scientifique }\end{array}$ & $256 \times 128$ \\
\hline CSIRO-Mk3-6-0 & CSIRO-QCCCE & $192 \times 96$ \\
\hline FGOALS-s2 & LASG-CESS & $128 \times 60$ \\
\hline HadCM3 & Geophysical Fluid Dynamics Laboratory & $96 \times 73$ \\
\hline GISS-E2-R & NASA Goddard Institute for Space Studies & $180 \times 72$ \\
\hline IPSL-CM5A-LR & L'Institut Pierre-Simon Laplace & $96 \times 96$ \\
\hline IPSL-CM5A-MR & L'Institut Pierre-Simon Laplace & $144 \times 143$ \\
\hline MIROC4h & $\begin{array}{l}\text { Atmosphere and Ocean Research Institute (University of Tokyo), National Institute for } \\
\text { Environmental Studies, and Japan Agency for Marine-Earth Science and Technology }\end{array}$ & $640 \times 320$ \\
\hline MIROC5 & $\begin{array}{l}\text { Atmosphere and Ocean Research Institute (University of Tokyo), National Institute } \\
\text { for Environmental Studies, and Japan Agency for Marine-Earth Science and Technology }\end{array}$ & $256 \times 128$ \\
\hline MIROC-ESM & $\begin{array}{l}\text { Japan Agency for Marine-Earth Science and Technology, Atmosphere and Ocean } \\
\text { Research Institute (University of Tokyo), and National Institute for Environmental Studies }\end{array}$ & $128 \times 64$ \\
\hline MPI-ESM-LR & Max Planck Institute for Meteorology (MPI-M) & $192 \times 96$ \\
\hline MPI-ESM-MR & Max Planck Institute for Meteorology (MPI-M) & $192 \times 96$ \\
\hline MRI-CGCM3 & Meteorological Research Institute & $320 \times 160$ \\
\hline NorESM1-M & Norwegian Climate Centre & $144 \times 96$ \\
\hline
\end{tabular}

Table 2. Details of the 17 CMIP5 climate models 
The median value was chosen to avoid the influences of large model errors on the results. For example, a negative relative error indicates that the model RMSE should be smaller than RMSE $E_{\text {median. Similar to }}$ Gleckler et al. (2008), normalizing the RMSE results is an effective way to compare a model's performance with that of another model. Accordingly, the performance of each model was assessed with respect to the 3 observational data sets (ADEX, HadEX2 and APHDEX) in the common period of 1961-2007.

The Taylor diagram (Taylor 2001) is generally used to summarize the different indices of ensemble mean model simulations for the purpose of evaluating the performances of the extreme indices. This diagram is used to compare the simulation performances of different precipitation extreme indices in 2 regards, namely, the spatial correlation coefficient and the spatial standard deviation (SD) ratio, with observational precipitation extreme indices. Each number corresponds to the performance of each precipitation extreme index with regard to its ensemble mean simulation. Angular and radial coordinates, respectively, represent the range of the correlation and the normalized SD (Gleckler et al. 2008), allowing the model simulations among the different indices to be displayed over Asia and its different sub-regions.

\section{RESULTS}

\subsection{Regional average climatologies}

Regional climatologies were computed for the observational data sets and model simulations over the period of 1961-2007, which is available for all of the data sets. The 3 data sets and the CMIP5 models were masked, and thus we used the same grids for the analysis. The average precipitation extreme indices during 1961-2007 over Asia and its subregions were computed for the CMIP5 models and the 3 observational data sets. The temporal averages of these indices over Asia and its sub-regions are shown in box-and-whisker plots (Fig. 2).

Over all of Asia and its sub-regions, ADEX and HadEX2 generally have similar values, and APHDEX has lower values than both ADEX and HadEX2 except with regard to CWD. ADEX and HadEX2 generally lie within the model spread except for Rx1day, SDII and the 2 duration indices; observational Rx1day, SDII and CDD exhibit the higher end of the simulated values while CWD exhibits the lower end of the simulated values. The model simulations display an excessive number of wet days (i.e. high CWD
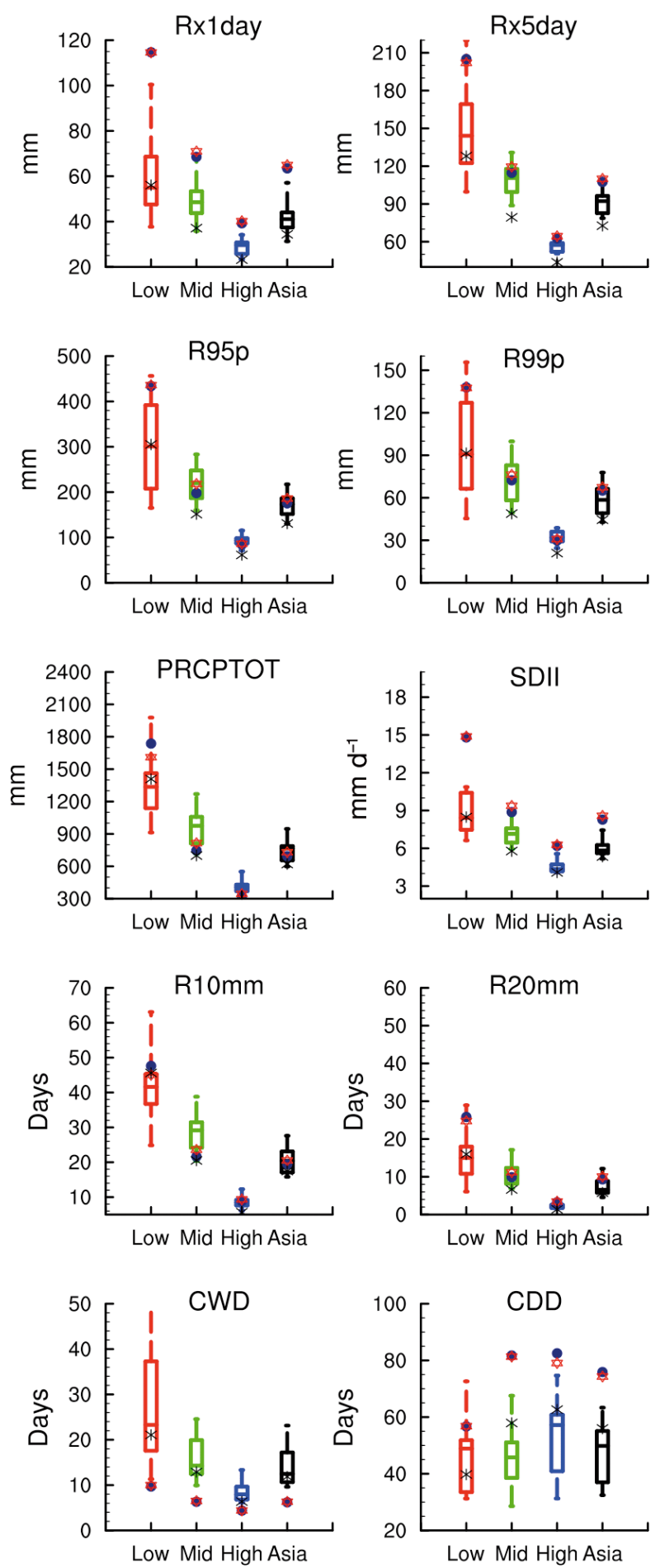

Fig. 2. Box-and-whisker plots of the extreme precipitation indices (see Table 1) calculated from the 17 CMIP5 models. Boxes: interquartile model spread (range between the 25th and 75th quantiles); midline: multi-model median; whiskers: total intermodal range during the period of 1961-2007. Black, blue, green and red: area averages over Asia and its 3 sub-regions, namely, the high-, mid- and low-latitude regions, respectively. Blue dots: ADEX; red asterisks: HadEX2; black crosses: APHDEX 
values) compared with the 2 observational data sets (HadEX2 and ADEX), while the model simulations generally underestimate Rx1day, Rx5day, CDD and SDII in Asia and its sub-regions. These findings agree well with previous studies that have shown this effect on a global scale (Sillmann et al. 2013a, Alexander \& Arblaster 2017). Over Asia and in the mid- and highlatitude regions, the model median values in the $2 \mathrm{ob}-$ servational data sets (ADEX and HadEX2) show slightly different performances.

The differences between the simulations and observational data sets are quite large in the low-latitude region. APHDEX shows a lower mean value than the other data sets that is closer to the median of the CMIP5 simulations, which may be associated with the low station coverage, the order of operations or the gridding method (Avila et al. 2015, Herold et al. 2016); that is, HadEX2 and ADEX calculate the indices for each station and then map them onto the grids, while APHDEX was calculated on each grid at a $1 \times 1^{\circ}$ resolution and was then interpolated on the coarser grid $\left(2.5 \times 3.75^{\circ}\right)$. When the data sets are changed, the intensity indices are more sensitive to the observations in Asia and the sub-regions, and the intensity indices (e.g. Rx1day and Rx5day) are more sensitive to the change in the data sets than the frequency indices (R10mm and R20mm).

The CMIP5 models also showed large uncertainties at low latitudes, which may be explained by the large climate difference in the models at low latitudes (O'Gorman \& Schneider 2009, Toreti et al. 2013). Lowintensity rainfall is simulated too frequently, while high-intensity rainfall is simulated too infrequently (Sillmann et al. 2013a). The simulated PRCPTOT, R10mm and CWD values in the mid-latitude region are all higher than those in HadEX2 and ADEX. Thus, we believe that the simulations yield a greater total precipitation in the mid-latitude region, mainly due to the contribution from low-frequency light precipitation.

The spatial patterns of CMIP5 ensemble mean and observational precipitation extreme indices (i.e. ADEX, HadEX2 and APHDEX) for the period 19612007 are shown in Fig. 3. The features of the spatial patterns in the 10 simulated precipitation extreme indices are similar to the observational precipitation extremes; the values for each index except for CDD are higher in Southeast China and lower in Northwest Asia. However, there are some differences between the simulations and observations, particularly for Southeast China, where the ensemble mean simulation shows lower Rx1day, Rx5day, R99p, SDII and CDD values and higher CWD values than either ADEX or HadEX2. Most of the indices in APHDEX are lower than those in the other 2 observational data sets, and the patterns of Rx1day, Rx5day, R99p and SDII are closer to the ensemble mean. Moreover, the number of grids in HadEX2 is less than that in either ADEX or APHDEX, especially for Rx1day, Rx5day, R95p and R99p. In addition, ADEX and APHDEX include many more precipitation stations in the Himalayas and Mongolia, and thus they have a greater spatial coverage than HadEX2.

The Taylor diagrams for the simulated precipitation extreme indices over Asia and its sub-regions during the period 1961-2007 are shown in Fig. 4. Generally, large index values are spread out over Asia and its different sub-regions. The correlations among the absolute intensity indices, relative intensity indices and SDII are higher than those among PRCPTOT, the frequency indices, the duration indices throughout Asia and the mid- and high-latitude regions. The ensemble mean simulation showed higher correlation values in HadEX2 than in ADEX and APHDEX that were closer to the reference values over Asia and most sub-regions for PRCPTOT and the frequency indices; thus, the simulated PRCPTOT and the frequency indices showed better performances in HadEX2 than in ADEX and APHDEX. Accordingly, the angular-distance weighting methodology may lead to a better performance and a higher correlation in HadEX2 with regard to R10mm, R20mm and PRCPTOT in the mid-latitude region. In the high-latitude region, the SDs of the ensemble mean simulations of Rx5day and R20mm show better performances in ADEX than in HadEX2. Moreover, the SDs of APHDEX for most indices except for CDD are larger than those of HadEX2 and ADEX, which are further from the reference values over all of Asia and its sub-regions.

Our results indicate that ADEX and HadEX2 are more similar, while APHDEX shows lower values than the other observational data sets in all indices except for the 2 duration indices. No substantial differences were found between the mean values of ADEX and HadEX2; most of the indices in the 2 observational data sets displayed small differences over Asia and its sub-regions. The values of Rx5day in addition to those of the relative intensity indices and frequency indices in ADEX and HADEX2 are closer to the model median values in the mid- and high-latitude regions. Large differences at low latitudes lead to larger deviations and lower APHDEX values than in the other 2 observational data sets; as a consequence, all of the indices in APHDEX are closer to the model median values at low latitudes, and the same holds for the duration indices over Asia and all 


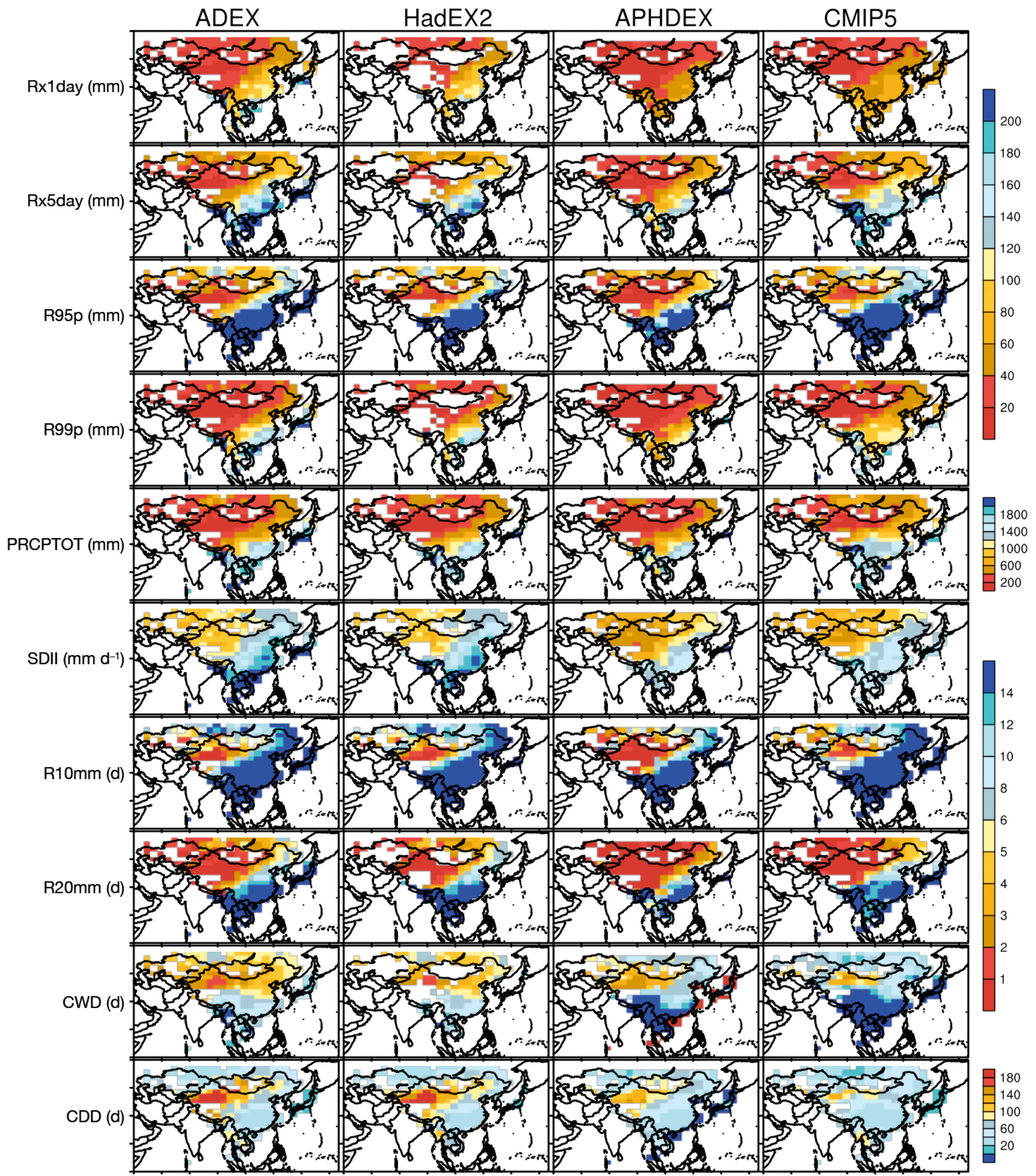

Fig. 3. Spatial distribution of the average values of the annual extreme precipitation indices (see Table 1) during 1961-2007 in the observational data sets (ADEX, HadEX2 and APHDEX) and the model-simulated ensemble mean (CMIP5). HadEX2, APHDEX and CMIP5 were masked by ADEX 
a) Low-latitude (1961-2007)
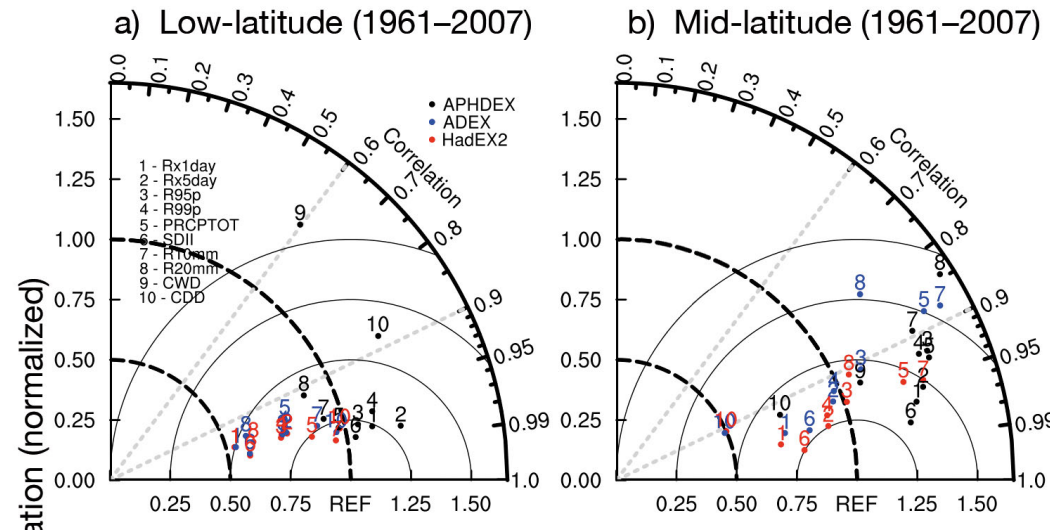

c) High-latitude (1961-2007)
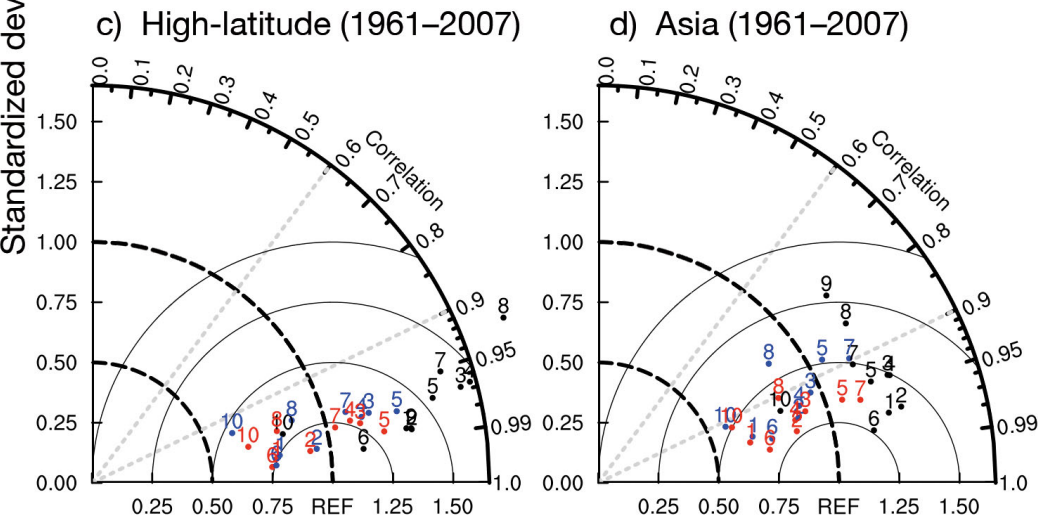

Fig. 4. Taylor diagrams of the CMIP5 ensemble mean in different regions (1961-2007): (a) low-latitude region; (b) mid-latitude region; (c) high-latitude region; and (d) all of Asia. The red dot represents the ensemble mean simulation for 10 indices compared with HadEX2, while the blue dot represents the comparison with ADEX and the black dot represents the comparison with APHDEX

of its sub-regions. The differences between the simulations and observational data sets are quite large in the low-latitude region. The intensity indices (i.e. Rx1day and Rx5day) are thus more sensitive to the data sets than the frequency indices (R10mm and R20mm).

\subsection{Trends over Asia and its sub-regions}

Fig. 5 shows the temporal evolution of the 10 precipitation extreme anomalies from the 3 data sets and 17 CMIP5 models (82 simulations) over all of Asia. The ADEX, HadEX2 and APHDEX data sets have different time periods of 1958-2012, 1958-2010 and 1961-2007, respectively. All of the anomalies in these data sets are relative to the base period of 1961-1990. Three of the observational data sets were masked to mimic the availability of shorter period observations over time and space when the period of one observa- tion was shorter than another; only the CMIP5 model was masked by ADEX. Fig. 5 shows that the time series of HadEX2 and ADEX are similar, but there are some notable differences, primarily in Rx1day, Rx5day, R95p and R99p during 2001-2009, indicating that these extremes in HadEX2 have greater precipitation extremes than those in ADEX, especially at low latitudes (Figs. S1-S3 in the Supplement at www.int-res.com/articles/ suppl/c076p161_supp.pdf). Observational precipitation indices generally have large variability in most cases, but CWD is an exception. The reason for this may be that the model simulations obtain higher CWD values (i.e. more wet days) than are observed, and thus the simulations output higher anomaly values. Some years of the observational range lie outside of the CMIP5 model simulations for most of the indices (Collins et al. 2013).

When the HadEX2 station data set (in which only public data were calculated, meaning that China was not included) was used to calculate each grid similar to the gridding method in ADEX, the differences between the results using this method and those in HadEX2 were small (Figs. S4-S7), except for those at low latitudes, and were large for Rx1day and Rx5day. Two approaches were used with the APHRODITE data set to calculate the annual gridded precipitation extreme indices: one interpolated the daily precipitation station data to the HadEX2 grid size before calculating the annual precipitation extreme indices at each grid; the other calculated the annual precipitation extreme indices in $1 \times 1^{\circ}$ grids and then interpolated those grids to the HadEX2 grid size. Consequently, most of the indices in APHRODITE showed large variations between the 2 approaches at low latitudes (Figs. S8S11). Therefore, a high spread, which has been shown to increase variance (Herold et al. 2016), tends to occur in areas with a low station density, especially at low latitudes. When the station network is sparse, the availability of an insufficient spatial coverage of daily observation stations will lead to a large bias in the gridding method, and the operational order of the methodology will have the most notable impact on the high-intensity rainfall (Rx1day and Rx5day). 

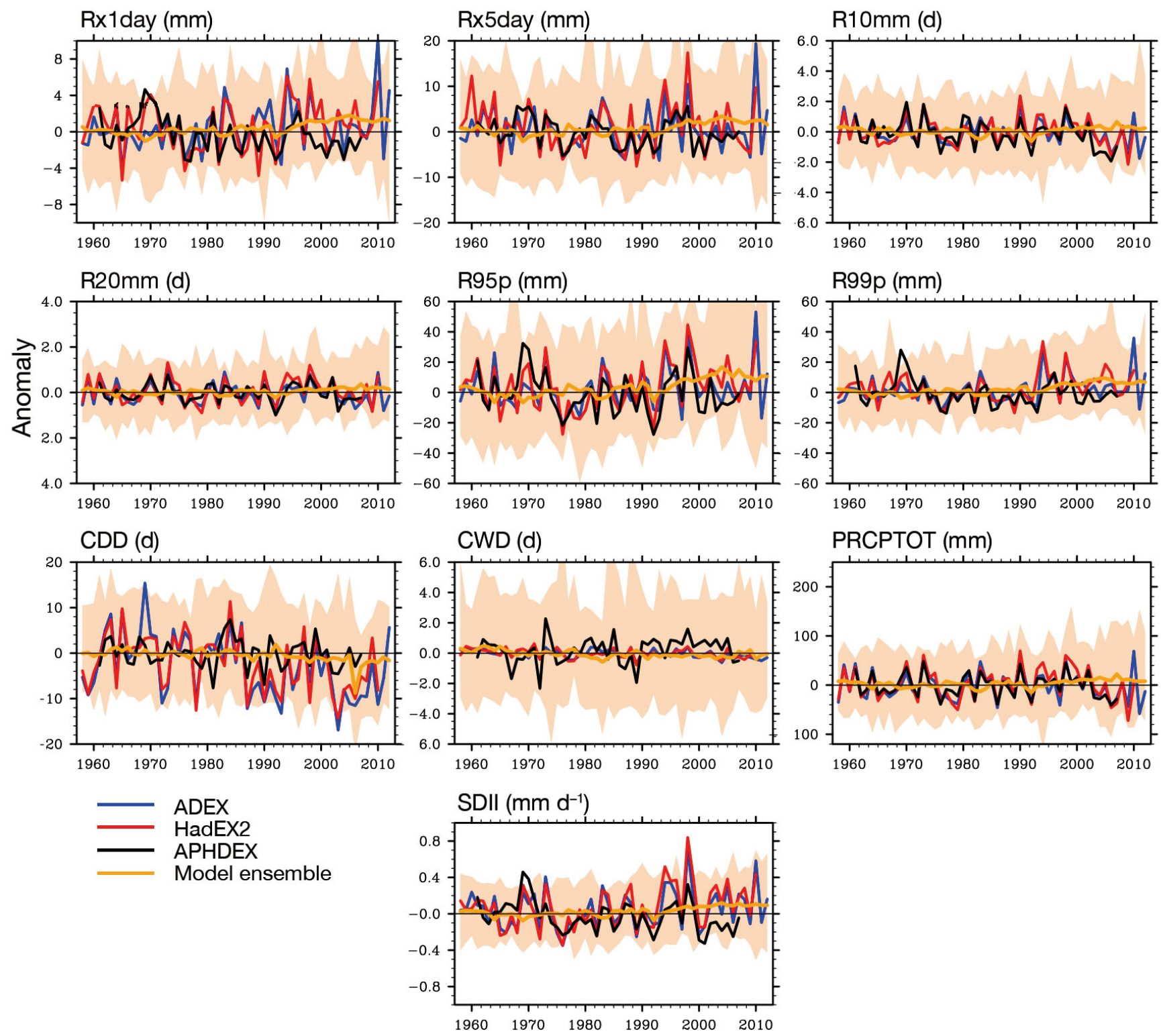

Fig. 5. Time series of mean regional average anomalies (relative to 1961-1990) for the precipitation extremes in the observations (blue lines: ADEX, 1958-2012; red lines: HadEX2, 1958-2010; black lines: APHDEX, 1961-2007) and the model simulations (1958-2012). Orange lines: multi-model ensemble means in the CMIP5 simulations

The mean linear regression slope for the model simulations and the 3 observational data sets over Asia and its sub-regions during 1961-2007 are shown in Fig. 6. The values in APHDEX are lower than those in ADEX and HadEX2 for most indices over Asia and the mid- and high-latitude regions, except for the duration indices. The results in ADEX and HadEX2 are more similar for SDII, R10mm, R20mm and CWD in the mid- and high-latitude regions. These results indicate that the simulated precipitation extreme trend is too strong in Rx5day, R95p, PRCPTOT and CDD over Asia, and the simu- lated SDII, R10mm, R20mm and CWD are closer to those in the 2 observational data sets (ADEX and HadEX2) in the mid- and high-latitude regions. Except for the duration indices, positive trends over Asia and its mid- and high-latitude regions were simulated by the climate models, but the absolute intensity (Rx1day and Rx5day), R10mm and PRCPTOT were significantly overestimated in most of the regions and over all of Asia.

The ADEX and APHDEX trends are generally lower than those of HadEX2 at low latitudes, where the uncertainties in the observational intensity 

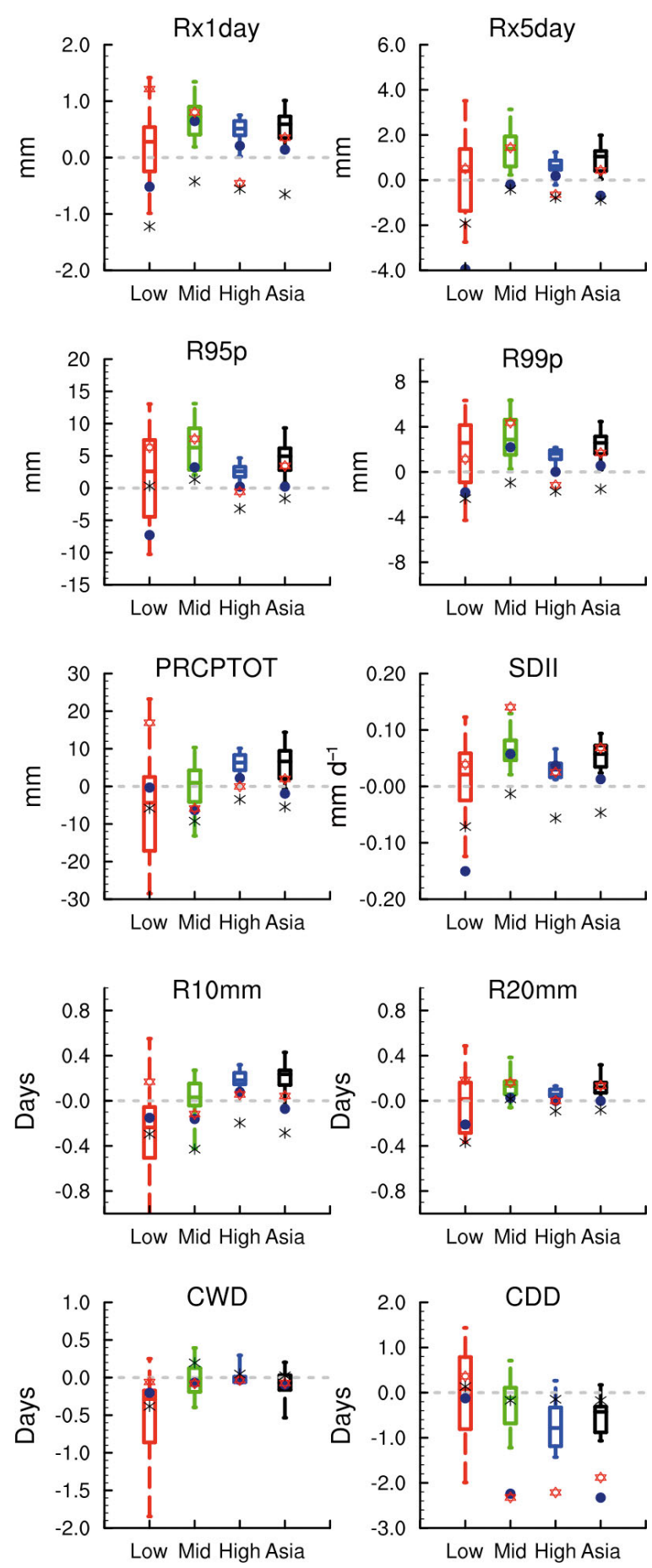

Fig. 6. Same as Fig. 2 but for the linear decadal trends in the precipitation extreme indices

indices are larger than those in the duration indices and frequency indices, and the intensity indices are more sensitive to the observational data sets. For all indices except the duration indices in the lowlatitude region, a larger discrepancy is observed for the trend of the precipitation extreme indices among the 3 observational data sets, and 3 data sets do not agree on the positive/negative trends, except for CWD

Over all of Asia, the trends of the model medians of most indices are closer to HadEX2 than either ADEX or APHDEX. The value of CDD in APHDEX is closer to the model median than that in the other 2 data sets. In the low-latitude region, $\mathrm{ADEX}$ is closer to the precipitation extreme of the model median than HadEX2 or APHDEX for Rx1day and CWD, and the values of R95p, PRCPTOT, R10mm and CDD are closer to the model median in APHDEX than in the other 2 observational data sets. In the mid-latitude region, the values of R99p, SDII and CDD in ADEX are closer to the model median simulation than HadEX2, while the values of Rx5day, R95p and R10mm in HadEX2 are closer to the model median value, and only CDD in APHDEX is closer to the model median value. In the high-latitude region, all of the intensity indices in ADEX are closer to the model median than HadEX2.

Fig. 7 shows the pattern of the linear regression slope for the CMIP5 model ensemble mean and the observational data sets (ADEX, HadEX2 and APHDEX) during 1961-2007. Compared with the temperature extremes, the changes in the precipitation extremes are generally more spatially complex at large scales, and their trends are largely less significant at the local scale (Donat et al. 2013). The ensemble mean showed an overestimation of the trend of most precipitation extremes compared with the observations over all of Asian and in the mid- and highlatitude regions. Most of the observational precipitation extremes are similar to the negative trends in a southwest-northeast belt from Southwest China to Northeast China, as Zhou et al. (2015) reported, and the changes in the observational precipitation extreme indices exhibit greater spatial heterogeneity than the model ensemble mean. The model mean failed to capture this characteristic in the intensity indices and did not capture the negative trends in Northeast China or the positive trend in Southeast China for PRCPTOT, R10mm, R20mm and CWD.

Our results indicate that the values of most indices (except the duration indices) in APHDEX are lower than those in ADEX and HadEX2 over Asia and the mid- and high-latitude regions. APHDEX is farther from the model median than the other 2 observational data sets, except some indices at low latitudes. The trends of ADEX and HadEX2 have some discrepancies over Asia and its sub-regions. Most of the simulated intensity index trends in ADEX show a better performance than those in HadEX2 in the high-lat- 


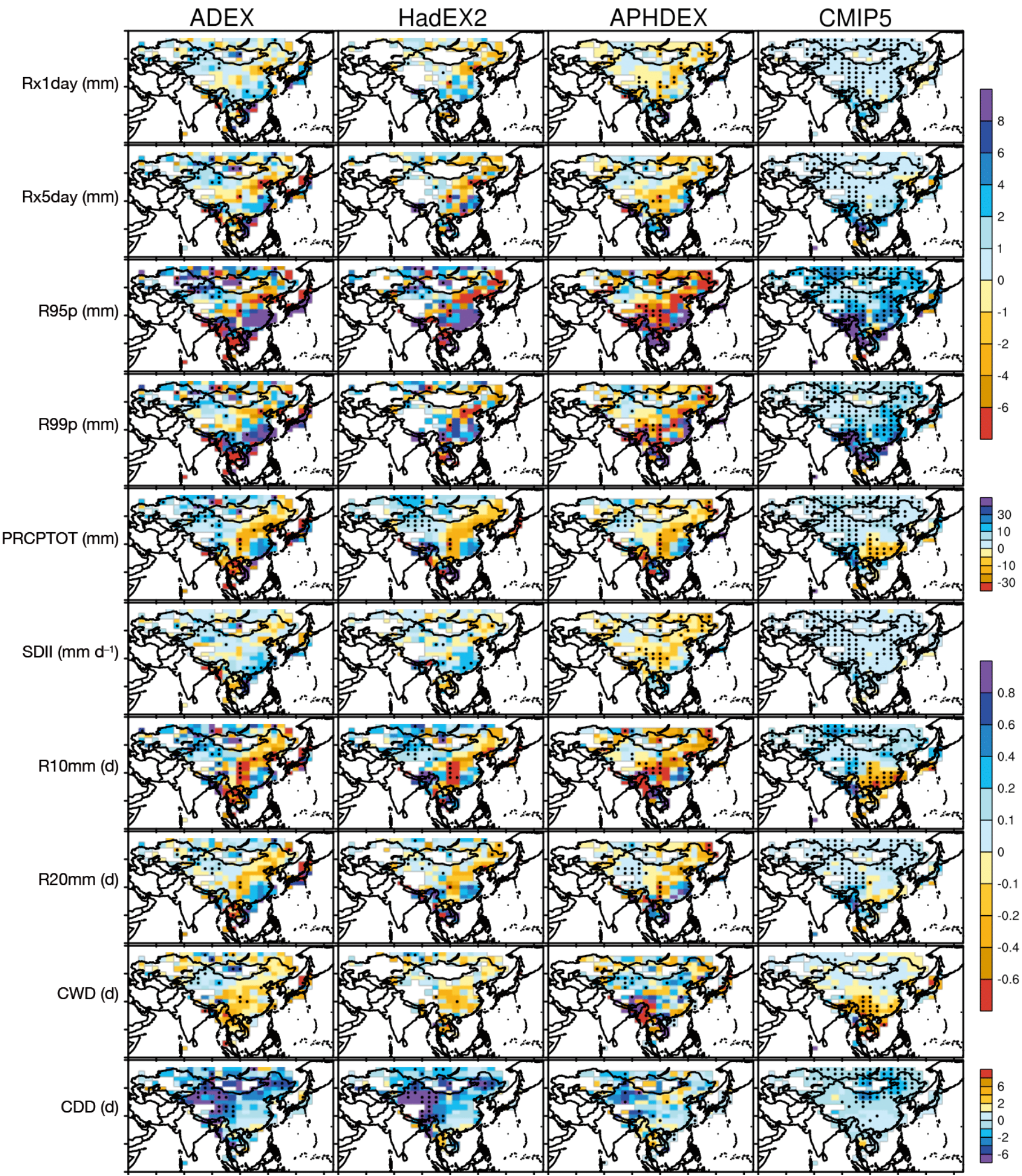

Fig. 7. Spatial distribution of the linear trend of the annual extreme precipitation indices during 1961-2007 in the observations (ADEX, HadEX2 and APHDEX) and model-simulated ensemble mean (CMIP5). Black dots indicate where the trends are significant at the $5 \%$ confidence level. HadEX2, APHDEX and CMIP5 were masked by ADEX 
itude region, that is, the model simulations appear to agree better with the trends in ADEX than with those in HadEX2 with regard to the precipitation intensity indices in the high-latitude region, while the simulated trends of most indices in HadEX2 show a better performance than those in ADEX over all of Asia. Only CDD in APHDEX is closer to the model median over Asia and in the mid- and high-latitude regions. At low latitudes, the uncertainties in the intensity indices among the 3 observational data sets and the model simulations are large.

\subsection{Metrics of the model performance ranking}

The RMSE' values of the different mean precipitation extreme indices in ADEX, HadEX2 and APHDEX over Asia and its sub-regions during the period of

\section{(a) Low-latitude}

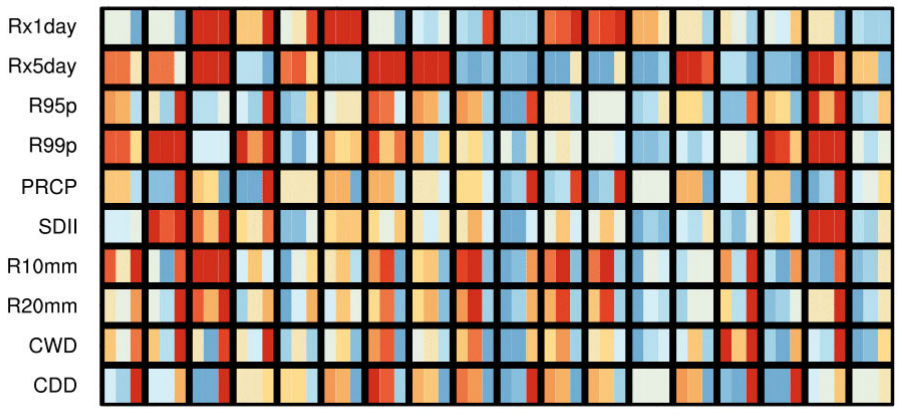

(c) High-latitude
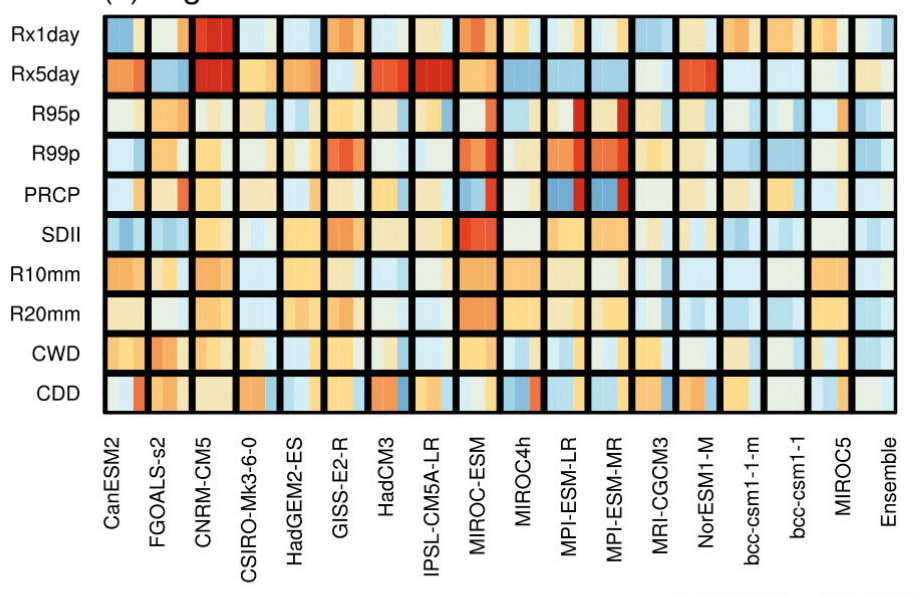

$$
\begin{array}{ccccccccc}
-0.4-0.2 & 0 & 0.2 & 0.4 & 0.6 & 0.8 \\
& \text { RMSE }
\end{array}
$$

(d) Asia
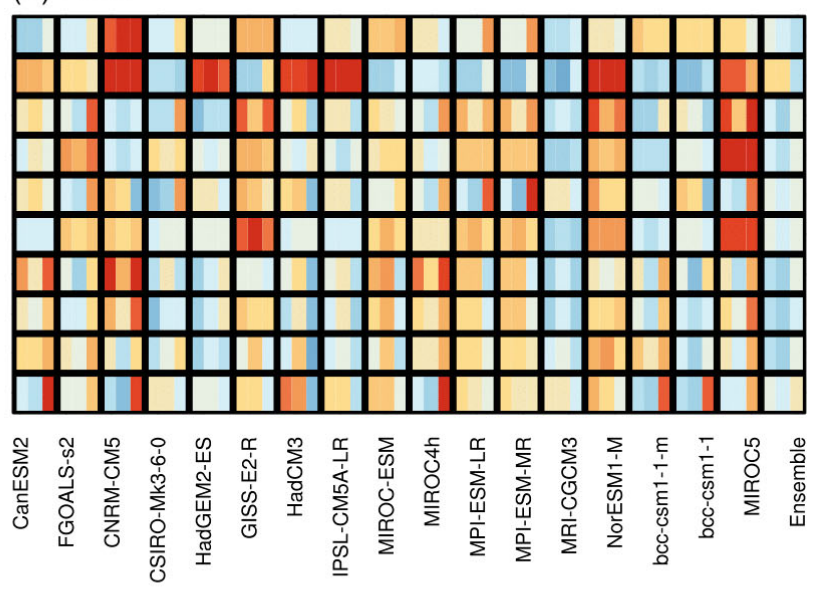

1961-2007 are shown in Fig. 8. An obvious feature is that the ensemble mean values are generally in better agreement with the observations than the typical model due to the offset of systematic errors in the individual models in addition to a high smoothing frequency and a smaller scale (Gleckler et al. 2008). This has been noted in other multi-model comparison studies (IPCC 2013, Dong et al. 2015), but the range of the different indices and models is more pronounced for the precipitation extremes here.

However, no one model is superior or inferior to another model in every respect. For example, MROC4h obtains higher scores in the low-latitude region but does not stand out elsewhere. Most indices are effectively simulated by some models, particularly in MRI-CGCM3. Moreover, higher-resolution models generally do not show better performances with regard to precipitation extreme indices

(b) Mid-latitude

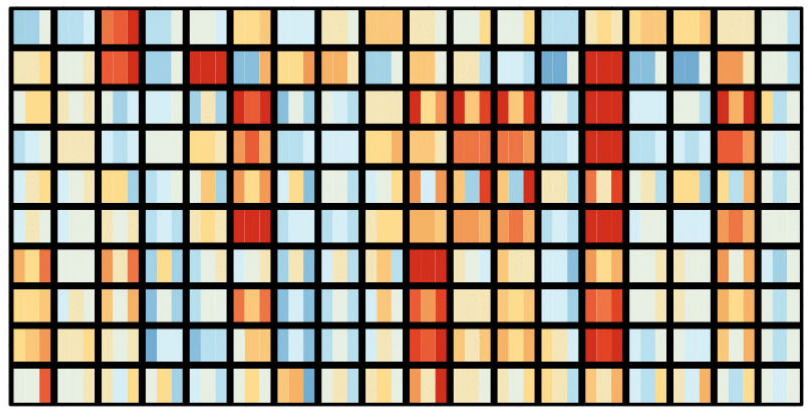

Fig. 8. Performances of the relative spatial mean root mean square errors (RMSEs) over Asia in the period of 1961-2007 in the climatologies of the extreme precipitation indices (column headings; see Table 1 for definitions) simulated by the 17 CMIP5 models (row headings; see Table 2 for further details) with respect to ADEX (left rectangle within each grid square), HadEX2 (middle rectangle) and APHDEX (right rectangle). (a) Low-latitude region; (b) mid-latitude region; (c) high-latitude region; and (d) all of Asia 
than lower-resolution models (Sillmann et al. 2013a). The multi-model ensemble mean errors in ADEX and HadEX2 over Asia and its sub-regions are larger in Rx5day than in the other indices. The multi-model ensemble mean errors in most of the intensity and frequency indices exhibit small differences compared with the 3 observational data sets. The simulation ensemble mean showed better performances in ADEX and HadEX2 than in APHDEX for most of the indices over Asia and its sub-regions. For the construction of the frequency indices, the multi-model ensemble mean in ADEX and HadEX2 generally showed good performances over Asia and its subregions and RMSE' values smaller than the intensity indices. The simulation mean RMSE' in APHDEX showed the best performance among the 3 observational data sets over Asia and its sub-regions only for Rx1day and Rx5day. Meanwhile, the simulated RMSE' in APHDEX achieved better performances at mid- and high latitudes than at low latitudes.

\section{DISCUSSION AND CONCLUSIONS}

This work comprehensively compared the CMIP5 models with 3 observational data sets (ADEX, HadEX2 and APHDEX) using 10 precipitation extreme indices over Asia and its different latitudinal regions. The differences in the precipitation extreme indices in the 3 observational data sets over Asia were assessed, and we also investigated whether the new observational data set (ADEX) can be utilized for extreme Asian precipitation studies.

We found that the model evaluation of extreme precipitation can be particularly affected by different data sets. Although APHDEX has a higher grid resolution than HadEX2, APHDEX may not be appropriate for evaluating Asian precipitation extremes in the CMIP5 model. Herold et al. (2017) demonstrated that the inter-product observational sensitivity is prominent at resolutions of $1 \times 1^{\circ}$ or finer; thus, differences would be amplified when evaluating precipitation extremes. Moreover, APHRODITE data have obvious deviations from HadEX2 and ADEX data in describing the climatology and the long-term changes in the precipitation frequency, intensity and duration (Han \& Zhou 2012, Yin et al. 2015). In addition, ADEX and HadEX2 also exhibit higher precipitation extreme values than APHDEX, except for the duration. The in situ data quality, the spatial and temporal coverage of the station network, and the operational order and interpolation methods are all important factors that cause uncertainties in observational data sets (Donat et al. 2014, Avila et al. 2015). This may lead to a spread in the precipitation extremes, thereby impacting the model evaluation. We also found discrepancies between the 3 observational data sets with regard to the spatial grid coverage. The difference in the spatial grid coverage between ADEX and HadEX2 is not consistent, and it depends greatly on the selected indices. For HadEX2, the spatial station coverage is not sufficient to detect actual changes in precipitation extremes (Donat et al. 2013), particularly with regard to Rx1day and Rx5day in this study. In contrast, ADEX has higher spatial grid/station coverage and provides more detailed information about climate extremes in Asia.

The time series in various data sets become increasingly noisy (and changes are often less significant) at low latitudes, while large internal climate variability is also found in the climate model simulations at low latitudes. The differences in most observational precipitation extreme indices are large at low latitudes, which is not encouraging. Furthermore, some authors have suggested that the uncertainties in the sensitivities of precipitation extremes to warming may be higher at low latitudes (O'Gorman 2015). In addition, the uncertainties in observational precipitation extreme indices (especially for Rx1day and SDII) are generally larger in the low-latitude region than in other regions. This may be explained by the low station coverage, different operational orders and different interpolation methods that mainly lead to these large uncertainties at low latitudes; low station coverage can be an important factor that leads to large differences. This study also confirms that the intensity indices (e.g. Rx1day and Rx5day) can be very sensitive to various observational data sets, while the frequency indices (R10mm and R20mm) are relatively insensitive to the different observational data sets.

There is also a large span in the different models at low latitudes that may be associated with the larger interquartile model spread and the different climate sensitivities of the models, in addition to positive regional land-atmosphere feedback processes (Toreti et al. 2013). Although the CMIP5 ensemble mean captured most of the spatial distribution of observed precipitation extremes during 1961-2007, the CMIP5 ensemble showed lower values for some intensity indices and higher values for CWD. Therefore, CMIP5 still underestimates the precipitation intensity and overestimates wet days in ADEX over Asia, as Sillmann et al. (2013a) and Alexander \& Arblaster (2017) noted in HadEX2. Furthermore, observational trends in precipitation extremes exhibit more spatial 
heterogeneity than the model ensemble mean. It is difficult for the model mean to capture the negative trends in Northeast China and the positive trend in Southeast China in some indices. Patterns in precipitation extremes can vary significantly in ADEX and HadEX2 given the topography (especially in the Himalayan Plateau) and the contrast between coastal areas and in-land areas at mid-latitudes, but topographic corrections are not performed in APHDEX. Large variations in precipitation extremes occur over small spatial scales, i.e. coastal locations and mountainous areas. Therefore, the coarse resolution of CMIP5 may not be suitable for capturing observation patterns, although this situation may be improved in CMIP6.

Some researchers have shown a global increase in the precipitation extreme intensity and frequency in HadEX2 (Alexander et al. 2006, Donat et al. 2013). This study similarly showed this pattern for most of the observational intensity and frequency indices over Asia. The models generally captured some of the trends in spatial patterns of the precipitation extremes over Asia; however, local changes are spatially more variable. The large uncertainties in the observations in our paper make the evaluation of model trend rather different (Sylla et al. 2013), especially at low latitudes. Over Asia and its sub-regions, the trends of some indices in ADEX in the mid-latitude region are similar to some researchers' results in China (Zhou et al. 2016). The differences in the trends between the observational data and the simulation uncertainties can also be quite large in the low-latitude region (e.g. the mean values). HadEX2 might be more appropriate for comparing trends in Asia, but the ADEX trend appears to agree better with the model-simulated trends than HadEX2 with regard to the frequency indices in the low-latitude region and the precipitation extreme intensity indices in the high-latitude region. We found that ADEX does not show a significant change compared with HadEX2 in the mid-latitude region, which may be explained by the ADW interpolation method, which involves the spatial correlation of the station data and minimizes the impact of data quality issues at individual stations upon averaging. HadEX2, which is likely more representative of point-based estimates of extremes, has relatively few observations (Donat et al. 2013). Moreover, HadEX2 has the smallest amount of station data in China among the 3 observational data sets, and it does not improve the results a great deal compared with ADEX. APHRODITE has $>700$ stations in China, but this observational data set has a substantially larger bias than either ADEX or HadEX2. The trend of HadEX2 in the western mid-latitudes was higher than that of ADEX, where the low station coverage led to a positive trend in HadEX2 in the mid-latitude region. In the future, improving the station coverage in the western mid-latitudes will be very important for Asian observations.

Additionally, the ensemble mean showed good performance in reproducing the trends of the precipitation extreme indices in ADEX in the high-latitude region; nevertheless, this observational data set may be suitable for detecting and attributing precipitation extremes, especially in high-latitude regions (Wan et al. 2015). Some observational data showed opposite trends compared with the CMIP5 models; this may make it difficult to detect and attribute precipitation extreme changes in some indices. We should also ensure that uncertainties in the observations are well understood depending on the observational data set we have chosen both for the region and for the indices employed for the detection and attribution. It is also important to apply new observational data sets that have quality control processes and high temporal and spatial resolutions (e.g. ADEX) to better understand precipitation extreme variations over Asia.

Acknowledgements. The International Workshop on Climate Data Requirements and Applications held in Nanjing, China, 4-8 March 2013, was jointly funded by the World Meteorological Organization and the China Meteorological Administration. We thank the workshop participants from the different Asian countries (i.e. the Asian region) for providing daily data and computing the indices during and after the Nanjing Workshop. S.D. and Y.S. are supported by the National Key R\&D Program of China (2018YFA0605604), the National Science Foundation of China (41675074) and Climate Change Project CCSF201805.

\section{LITERATURE CITED}

Alexander LV, Zhang X, Peterson TC, Caesar J and others (2006) Global observed changes in daily climate extremes of temperature and precipitation. J Geophys Res 111:D05109

Alexander LV (2016) Global observed long-term changes in temperature and precipitation extremes: a review of progress and limitations in IPCC assessments and beyond. Weather Clim Extrem 11:4-16

Alexander LV, Arblaster JM (2017) Historical and projected trends in temperature and precipitation extremes in Australia in observations and CMIP5. Weather Clim Extrem 15:34-56

Avila FB, Dong S, Menang KP, Rajczak J, Renom M, Donat MG, Alexander LV (2015) Systematic investigation of gridding-related scaling effects on annual statistics of daily temperature and precipitation maxima: a case study for south-east Australia. Weather Clim Extrem 9:6-16

Cao L, Zhu Y, Tang G, Yan Z (2016) Climatic warming in 
China according to a homogenized data set from 2419 stations. Int J Climatol 36:4384-4392

Collins M, AchutaRao K, Ashok K, Bhandari S and others (2013) Observational challenges in evaluating climate models. Nat Clim Chang 3:940-941

Donat MG, Alexander LV, Yang H, Durre I and others (2013) Updated analyses of temperature and precipitation extreme indices since the beginning of the twentieth century: the HadEX2 dataset. J Geophys Res Atmos 118: 2098-2118

Donat MG, Sillmann J, Wild S, Alexander LV, Lippmann T, Zwiers F (2014) Consistency of temperature and precipitation extremes across various global gridded in situ and reanalysis datasets. J Clim 27:5019-5035

Dong SY, Xu Y, Zhou BT, Shi Y (2015) Assessment of indices of temperature extremes simulated by multiple CMIP5 models over China. Adv Atmos Sci 32:1077-1091

Dong S, Sun Y, Aguilar E, Zhang X, Peterson TC, Song L, Zhang Y (2018) Observed changes in temperature extremes over Asia and their attribution. Clim Dyn 51: 339-353

Fischer EM, Knutti R (2015) Anthropogenic contribution to global occurrence of heavy-precipitation and hightemperature extremes. Nat Clim Chang 5:560-564

Freychet N, Hsu HH, Wu CH (2016) Extreme precipitation events over East Asia: evaluating the CMIP5 mode atmospheric hazards. Atmospheric hazards: case studies in modeling, communication, and societal impacts. ExLi4EvA, p 87-109

Gleckler PJ, Taylor KE, Doutriaux C (2008) Performance metrics for climate models. J Geophys Res 113:D06104

Han ZY, Zhou TJ (2012) Assessing the quality of APHRODITE high-resolution daily precipitation datasets over contiguous China. Chin J Atmos Sci 36:361-373 (in Chinese)

Herold N, Alexander LV, Donat MG and others (2016) How much does it rain over land? Geophys Res Lett 43:341-348

Herold N, Behrangi A, Alexander LV (2017) Large uncertainties in observed daily precipitation extremes over land. J Geophys Res Atmos 122:668-681

IPCC (2013) Climate change 2013: the physical science basis. Contribution of Working Group I to the Fifth Assessment Report of the Intergovernmental Panel on Climate Change. Cambridge University Press, Cambridge

IPCC (2014) Climate change 2014: impacts, adaptation, and vulnerability. Part A. Global and Sectoral Aspects. Contribution of Working Group II to the Fifth Assessment Report of the Intergovernmental Panel on Climate Change. Cambridge University Press, Cambridge

Jiang Z, Li W, Xu J and others (2015) Extreme precipitation indices over China in CMIP5 models. I. Model evaluation. J Clim 28:8603-8619

Menne MJ, Durre I, Vose RS and others (2012) An overview of the global historical climatology network-daily database. J Atmos Ocean Technol 29:897-910

Mestre O, Domonkos P, Picard F and others (2013) HOMER: a homogenization software-methods and applications. Quart J Hungarian Meteorol Serv 117:47-67

' O'Gorman PA (2015) Precipitation extremes under climate change. Curr Clim Change Rep 1:49-59

* O'Gorman PA, Schneider T (2009) The physical basis for increases in precipitation extremes in simulations of 21st-century climate change. Proc Natl Acad Sci USA 106:14773-14777

Ou T, Chen D, Linderholm HW, Jeong JH (2013) Evaluation of global climate models in simulating extreme precipita- tion in China. Tellus A Dyn Meterol Oceanogr 65:1

* Peterson TC, Manton MJ (2008) Monitoring changes in climate extremes: a tale of international collaboration. Bull Am Meteorol Soc 89:1266-1271

* Polson D, Hegerl G, Zhang X, Osborn T (2013) Causes of robust seasonal land precipitation changes. J Clim 26: 6679-6697

Sheffield J, Barrett AP, Colle B and others (2013) North American climate in CMIP5 experiments. I. Evaluation of historical simulations of continental and regional climatology. J Clim 26:9209-9245

Sillmann J, Kharin VV, Zhang X, Zwiers FW, Bronaugh D (2013a) Climate extremes indices in the CMIP5 multimodel ensemble. 1. Model evaluation in the present climate. J Geophys Res 118:1716-1733

Sillmann J, Kharin VV, Zwiers FW, Zhang X, Bronaugh D (2013b) Climate extremes indices in the CMIP5 multimodel ensemble. 2. Future climate projections. J Geophys Res 118:2473-2493

* Sylla MB, Giorgi F, Coppola E and others (2013) Uncertainties in daily rainfall over Africa: assessment of gridded observation products and evaluation of a regional climate model simulation. Int J Climatol 33:1805-1817

Taylor KE (2001) Summarizing multiple aspects of model performance in a single diagram. J Geophys Res 106: 7183-7192

Taylor KE, Stouffer RJ, Meehl GA (2012) An overview of CMIP5 and the experiment design. Bull Am Meteorol Soc 93:485-498

Toreti A, Naveau P, Zampieri M and others (2013) Projections of global changes in precipitation extremes from Coupled Model Intercomparison Project Phase 5 models. Geophys Res Lett 40:4887-4892

WWan H, Zhang X, Zwiers FW and others (2013) Effect of data coverage on the estimation of mean and variability of precipitation at global and regional scales. J Geophys Res Atmos 118:534-546

*Wan H, Zhang X, Zwiers F and others (2015) Attributing northern high-latitude precipitation change over the period 1966-2005 to human influence. Clim Dyn 45: 1713-1726

Wang XL, Feng Y (2010) RHtestsV3 user manual. Climate Research Division, Science and Technology Branch, Environment Canada, Toronto

*Yatagai A, Kamiguchi K, Arakawa O and others (2012) APHRODITE: Constructing a long-term daily gridded precipitation dataset for Asia based on a dense network of rain gauges. Bull Am Meteorol Soc 93:1401-1415

Yin H, Donat MG, Alexander LV and others (2015) Multidataset comparison of gridded observed temperature and precipitation extremes over China. Int J Climatol 35: 2809-2827

Zhang X, Aguilar E, Sensoy S, Melkonyan H and others (2005) Trends in Middle East climate extreme indices from 1950 to 2003. J Geophys Res Atmos 110:D22104

* Zhang X, Zwiers FW, Hegerl GC, Lambert FH and others (2007) Detection of human influence on twentieth century precipitation trends. Nature 448:461-465

Z Zhang X, Wan H, Zwiers FW, Hegerl GC, Min SK (2013) Attributing intensification of precipitation extremes to human influence. Geophys Res Lett 40:5252-5257

Zhou B, Xu Y, Wu J, Dong SY, Shi Y (2016) Changes in temperature and precipitation extreme indices over China: analysis of a high-resolution grid dataset. Int J Climatol 36:1051-1066 